\title{
PENGEMBANGAN AGROWISATA SUBAK GULINGAN DI KECAMATAN MENGWI KABUPATEN BADUNG
}

\author{
I.A.L. Dewi ${ }^{1}$, I D.A.S. Yudhari², dan I.M. Mega ${ }^{3}$
}

\begin{abstract}
ABSTRAK
Pengabdian yang bertujuan untuk mengembangkan agrowisata subak di Desa Gulingan Kecamatan Mengwi Kabupaten badung. Kegiatan yang dilakukan meliputi persiapan, operasional dan evaluasi. Kegiatan persiapan terdiri dari rekrutmen peserta $\mathrm{KKN}$, kordinasi dengan mitra, pembekalan mahasiswa hingga mobilisasi mahasiswa ke lokasi. Kegiatan operasional meliputi: (1) Penataan jalan subak menjadi jalur tracking bagi wisatawan menikmati alam persawahan dan atraksi wisata aktivitas subak; (2) Penguatan kelembagaan subak menjadi pengola daya tarik agrowisata dan pelatihan tenaga pemandu; (3) Pengembangan aktivitas subak menjadi atraksi wisata; (5) Pelatihan pengolahan hasil pertanian dan ikan sebagai hidangan untuk wisatawan bagi wanita tani. Kegiatan evaluasi dilakukan secara berkelanjutan terhadap kemajuan yang diperoleh.
\end{abstract}

Kata Kunci : pengembangan, agrowisata, subak

\begin{abstract}
The community sevice aims to develop subak agrotourism in the Village Gulingan Mengwi Badung Regency. Activities include preparation, operation and evaluation. Preparatory activities consist of recruitment of KKN participants, coordination with partners, student briefing and student mobilization to the location. Operational activities include: (1) Arrangement of subak road into tracking track for tourists to enjoy the nature of rice fields and tourist attractions subak activities; (2) Institutional strengthening of subak into agro-tourism attraction and training of guide personnel; (3) The development of subak activities into tourist attractions; (5) Training the processing of agricultural products and fish as a meal for tourists for women farmers. Evaluation activities are carried out continuously on the progress made.
\end{abstract}

Keywords : development, agrotourism, subak

\section{PENDAHULUAN}

Desa Gulingan merupakan desa tradisional Bali yang terletak di Kecamatan Mengwi, Kabupaten Badung, Bali dan berjarak sekitar $20 \mathrm{~km}$ dari Kota Denpasar. Luas wilayah mencapai 760,384 hektar, dengan penggunaan lahan yang masih didominasi oleh lahan sawah. Pertanian lahan sawah di Desa Gulingan, seperti halnya pertanian lahan sawah di Bali pada umumnya dikelola dalam organisasi yang disebut Subak. Subak adalah organisasi tradisional petani di Bali yang bergerak dalam pengaturan air irigasi bersifat sosio-religius berlandaskan filosofi trihitha karana.

${ }^{1}$ Staf Pengajar Fakultas Pertanian Universitas Udayana, listiadewi60@yahoo.co.id

${ }^{2,3}$ Staf Pengajar Fakultas Pertanian Universitas Udayana 
Trihitha karana adalah falsafah hidup masyarakat Bali yang bermakna bahwa tiga penyebab kebahagiaan. Etnik Bali menyakini bahwa kebahagiaan akan tercapai bila terjadi hubungan yang harmonis antara manusia dengan tuhan, sesama manusia, dan alam. Subak sebagai sebuah implementasi trihitha karana terdiri dari tiga unsur yaitu unsur parahyangan, pawongan, dan palemahan. Parahyangan menyangkut berbagai nilai dan ritual keagamaan yang dilakukan sebagai wujud pemujaan kepada sang pencipta agar usaha tani yang dilakukan berhasil. Pawongan menyangkut interaksi sosial antara petani anggota subak agar selalu rukun dan bergotong royong dalam bercocok tanam dan adil dalam tatakelola air irigasi. Unsur palemahan adalah landscape persawahan sebagai tempat tumbuh tanaman dan habitat bagi berbagai binatang sawah. Ketiga unsur tersebut harus dalam kesimbangan agar terjadi harmonisasi dalam kehidupan subak. Taat trihita karana dan tradisi masih tetap dijunjung tinggi di Subak Gulingan. Oleh sebab itu, bila berkunjung ke wilayah ini pengunjung akan disuguhi pemandangan hamparan lahan persawahan berteras yang masih lestari, burung-burung sawah dari berbagai spesies, ikan air tawah seperti gurami, mujair, belut dan lele dan lain-lain masih banyak dijumpai. Begitu pula dengan aktivitas bercocok tanam tradisional masih banyak dilakukan seperti metekap (mengolah tanah dengan sapi), menanam padi, atau sistem distribusi air irigasi yang berkeadilan sangat menarik untuk dinikmati. Selain itu, kegiatan ritual anggota subak untuk memuja Dewi Sri sebagai manisfestasi tuhan dalam menjaga kehidupan tanaman tidak kalah menariknya untuk disimak. Setiap fase dari serangkaian fase bercocok tanam selalu disertai dengan ritual seperti menanam padi, keluar buah, panen bahkan pembrantasan hama dan penyakit tanaman juga diikuti dengan ritual yang disebut nangluk merana. Keterpaduan suasana alam dengan aktivitas budaya yang adiluhung sungguh menjadi daya tarik yang luar biasa bagi wisatawan.

Subak Gulingan, bila ditinjau dari aspek pariwisata memiliki posisi yang sangat strategis karena lokasinya yang berdekatan dengan Pura Taman Ayun. Pura Taman Ayun merupakan objek pariwisata budaya terkemuka di Kabupaten Badung yang sudah termasyur di seluruh dunia. Pura tersebut memiliki langgam arsitektur yang sangat unik dan memiliki nilai sejarah yang tinggi terkait dengan sejarah kerajaan Mengwi sebagai salah satu kerajaan besar di Bali pada masa lampau. Pure Taman Ayun dikelilingi oleh kolom dengan mata air besar yang menjadi sumber air irigasi bagi lahan sawah di Kabupaten Badung bagian hilir. Kelestarian kawasan Pure Taman Ayun guna menjaga kelestarian mata iair. Oleh sebab itu, pure tersebut telah ditetapkan sebagai salah satu warisan pusaka dunia oleh UNESCO. Pura dikunjungi oleh tidak kurang dari satu juta wisatawan setiap tahunnya.

Namun demikian, keindahan lahan persawahan dan keunikan kehidupan bercocok tanam anggota subak, serta lokasi strategis subak Gulingan ternyata belum mampu memberikan pendapatan yang mencukup bagi petani. Harga komoditas pertanian terutama padi dan ikan air tawar masih rendah dan sangat fluktuatif bila musim panen. Pendapatan rata-rata dari hasil pertanian hanya berkisara antara Rp. 750.000 sampai Rp. 1.000 .000 per bulan. Begitu pula dengan potensi pariwisata belum digarap dengan optimal sehingga tidak mampu memberikan nilai tambah bagi petani anggota subak karena lemahnya kemampuan sumber daya petani dalam bidang pariwisata. Wisatawan yang datang terbatas melihat pemandangan saja sehingga manfaat hanya dinikmati oleh travel agen saja. Rendahnya pendapatan dari kegiatan bertani menyebabkan pertanian mulai ditinggalkan oleh generasi muda, yang pada akhirnya akan mengancam kelestarian subak Gulingan itu sendiri.

Dalam rangka meningkatkan pendapatan petani di Desa Gulingan, Pemerintah Kabupaten Badung mengembangkan program integrasi pertanian (sawah) dengan periwisata dengan menetapkan Desa Gulingan sebagai Kawasan Daya tarik Agrowisata Subak. Agrowisata merupakan salah satu jenis wisata yang memanfaatkan usaha pertanian (agro) menjadi suatu objek wisata (Sutjipta, 2008). Melalui pengembangan agrowisata yang menonjolkan budaya lokal dalam memanfaatkan lahan, pendapatan petani diharapkan dapat ditingkatkan dan sekaligus melestarikan sumber daya lahan, serta memelihara budaya maupun teknologi lokal yang umumnya sesuai dengan kondisi lingkungan alaminya. Konsepsi agrowisata subak adalah menata dan eksploitasi potensi subak meliputi keindahan alam dan kehidupan sosial budaya masyarakat petani setempat khususnya

\section{1 | BULETIN UDAYANA MENGABDI}


aktivitas subak menjadi daya tarik wisata bagi wisatawan. Wisatawan menikmati paket wisata yang ditawarkan dengan melakukan perjalanan melihat alam subak dan aktivitasnya, mengikuti keseharian subak sebagai atraksi wisata, serta dapat menikmati hasil pangan yang dihasilkan olah subak bersangkutan. Agar program ini berjalan efektif sangat diperlukan adanya regulasi dan pemberdayaan masyarakat melalui pendampingan Perguruan Tinggi. Fungsi dari pendamping adalah sebagai: inisiator, motivator, fasilitator, inovator dan komunikator dalam pembangunan secara luas. Pendampingan dilakukan dengan melibatkan mahasiswa sebagai agen utama dibawah kordinasi dosen pembimbing lapangan. Dalam konteks ini, kegiatan pendampingan akan dilakukan melalui program Kuliah Kerja Nyata Pemberdayaan Masyarakat (KKN-PPM).

\section{METODE PELAKSANAAN}

Metode yang diterapkan dalam pemberdayaan masyarakat pada kegiatan KKN PPM adalah sebagai berikut: Kordinasi dan komunikasi secara partisipasif dengan masyarakat sasaran untuk merumuskan program mulai dari perencanaan, operasional dan evaluasi; Survei lapangan untuk pemetaan jalur tracking; Perancangan Website sebagai media promosi secara on line; Penyuluhan untuk membangun persepsi dan pemahaman masyarakat mengenai inovasi atau program yang diterapkan; Pelatihan dan simulasi terapan ipeks (demplot) yang dialihkan bagi masyarakat; Pendampingan yaitu pertemuan secara berkala dan berkelanjutan antara pendamping dengan masyarakat sasaran hingga ipteks yang dialihkan dapat dilaksanakan secara mandiri oleh masyarakat.

\section{HASIL DAN PEMBAHASAN}

\section{A. Penataan Jalan Subak menjadi jalur tracking bagi wisatawan}

Berdasarkan hasil koordinasi dengan pimpinan Desa Gulingan pada minggu pertama setelah mahasiswa kkn di lapangan, diperoleh informasi bahwa pimpinan desa telah memiliki rencana jalur tracking. Terdapat dua jalur tracking yang direncanakan oleh kepala desa yang satu melalui pintu masuk Taman Ayun dan jalur melalui Subak Bulan. Setelah berkoodinasi kemudian mahasiswa KKN PPM Desa Gulingan yang ada di bidang pengembangan fisik turun menelusuri kedua jalur tracking yang diberikan bersama dengan staf desa. Setelah turun mengetahui jalur-jalur tersebut kemudian mahasiswa berkoordinasi kembali dengan kepala desa dan memaparkan hasil pengamatan mereka, potensi dan kekurangan-kekurangan yang mesti dibenahi. Kemudian kepala desa, mahasiswa, dan DPL turun kembali menelusuri jalur tracking sambil mengecek kebenaran informasi mahasiswa. Penelusuran tahap kedua ini mahasiswa juga mengambil titik-titik koordinat GPS untuk pembuatan peta jalur tracking. Hasil luaran dari kegiatan ini adalah peta jalur tracking.

\section{B. Pengelolaan aktivitas subak dan kelompok masyarakat menjadi atraksi wisata}

Berdasarkan jalur yang dipilih, maka kepala desa memutuskan menggunakan jalur pintu masuk Taman Ayu. Disana terdapat bendung tempat pengaturan air irigasi yang mengairi lahan persawahan di Desa Gulingan. Setelah menelusuri sungai terebut maka wisatawan diajak masuk ke permukiman masyarakat, dan merasakan budaya masyarakat setempat. Setelah itu wisatawan akan diajak masuk ke kelompok pengerajin patung, pembuatan tedung, Dalam penentuan aktivitas subak kepala desa memiliki rencana akan menyediakan satu luasan lahan yang akan dapat dipergunakan sebagai tempat atraksi kegiatan menanam padi secara tradisional. Lahan yang dipergunakan adalah lahan milik kelian dinas Tengah Kaler, dengan sistem sewa. Di lahan tersebut wisatawan dapat ikut merasakan cara memanan padi dengan sisten taman mundur. Dilahan tersebut juga akan

VOLUME 17 NOMOR 02, APRIL 2018 | 12 
dipersiapkan peralatan penanaman budidaya padi secara tradisional, seperti tengala, tegteg, sunari, dan lelakut. di milik salah seorang petani di Desa Gulingan.

\section{Penguatan Kelembagaan subak menjadi pengola daya tarik agrowisata dan pelatihan guide lokal}

Dalam pembentukan suatu agrowisata ada empat elemen penting yang harus ada salah satunya adalah kelembagaan pengelola daya tarik agrowisata. Lembaga pengelola daya tarik agrowisata disebut kelompok sadar wisata (pokdarwis). Kondisi di Desa Gulingan belum memiliki kelompok sadar wisata, maka dibentuklah pokdarwis. Pembentukan pokdarwis di Desa Gulingan berkoordinasi dengan seluruh kelihan dinas, untuk membantu proses perekrutan warga sekitar menjadi pengelola pokdarwis. Setelah terbentuk kelompok sadar wisata (pokdarwis) maka diberikanlah wawasan dan tambahan pelatihan sebagai guide lokal. Jumlah peserta pelatihan adalah sebanyak 15 orang. Pelatihan dilaksanakan tanggal 14 Agustus 2017, dilaksanakan di Kantor Kepala Desa Gulingan. Pada pelatihan ini diserahkan bantuan seragam kerja kelompok sadar wisata.

\section{Pelatihan Alih teknologi pemanfaatan hama keong/kakul sebagai pakan entok sebagai pakan ramah lingkungan.}

Ide pelatihan alih teknologi pemanfaatan hama keong sebagai pakan unggas entok sehubungan maraknya keluhan petani lahan basah di Desa Gulingan yang lahannya diserang hama keong. Pelatihan ini diikuti oleh Kelompok Ternak Entok sebanyak delapan orang. Pelatihan dilaksanakan di rumah kediaman ketua kelompok ternak entok pada hari Senin tanggal 14 Agustus 2017. Pada pelatihan ini diserahkan bantuan pakan entok berupa konsentrat bahan dasar pencampur keong dan mikro organism lokal (MOL).

\section{F. Pelatihan pengolahan hasil pertanian dan budidaya entok menjadi produk kuliner dan jajanan khas hidangan wisata}

Kuliner merupakan salah satu elemen pendukung kegiatan agrowisata. Ketersediaan kuliner dan jajanan penting untuk menambahkan jasa servis yang akan dijual dalam kegiatan agrowisata. Kuliner andalan Desa Gulingan dalam mendukung kegiatan agrowisatanya adalah Guling Entok, sedangkan jajanan yang akan dikembangkan adalah pie susu dan bolu berbahan dasar labu. Entok dan labu merupakan bahan dasar lokal yang tidak sulit untuk diperoleh di Desa Gulingan sehingga pengalokasisan biaya bisa lebih ditekan dan harga jual menjadi lebih baik. Berdasarkan hal tersebut maka dibuatlah pelatihan pengolahan hasil pertanian dan budidaya Entok menjadi produk kuliner dan jajanan khas hiding wisata yang diikuti oleh ibu-ibu Kelompok Wanita Tani (KWT) Sekar Sandat. Pelatihan tersebut dilaksanakan pada hari minggu tanggal 13 Agustus 2017 di kediaman ibu sekertaris KWT Sekar Sandat. Jumlah anggota KWT Sekar sandat yang mengikuti pelatihan sebanyak 10 orang.

\section{KESIMPULAN DAN SARAN}

Kegiatan KKN PPM Desa Gulingan dilaksanakan dalam tiga tahap, tahap persiapan, operasional, dan evaluasi. Kegiatan persiapan dilaksanakan dalam lima tahap, yaitu koordinasi dengan calon sasaran program KKN PPM yaitu Desa Gulingan, Kabupaten Badung, Koordinasi dengan calon mitra KKN PPM, pemda Kabupaten Badung, Dinas Pariwisata Kabupaten Badung, Travelagent, pendaftaran dan seleksi mahasiswa sebagai calon peserta, sosialisasi program KKN PPM kepada mahasiswa sebagai calon peserta, mobilisasi mahasiswa KKN PPM ke Desa Gulingan. Tahap operasional meliputi enam tahap yaitu penataan Jalan Subak menjadi jalur tracking bagi wisatawan, pengelolaan aktivitas subak dan kelompok masyarakat menjadi atraksi wisata, 


\section{I.A.L. Dewi, I D.A.S. Yudhari, dan I M. Mega}

penguatan kelembagaan subak menjadi pengola daya tarik agrowisata dan pelatihan guide lokal, pelatihan alih teknologi pemanfaatan hama keong/kakul sebagai pakan entok sebagai pakan ramah lingkungan, pelatihan budidaya Entok, dan Pelatihan pengolahan hasil pertanian dan budidaya entok menjadi produk kuliner dan jajanan khas hidangan wisata. Hingga pertengahan agustus 2017 program kegiatan telah berjalan sebesar $70 \%$.
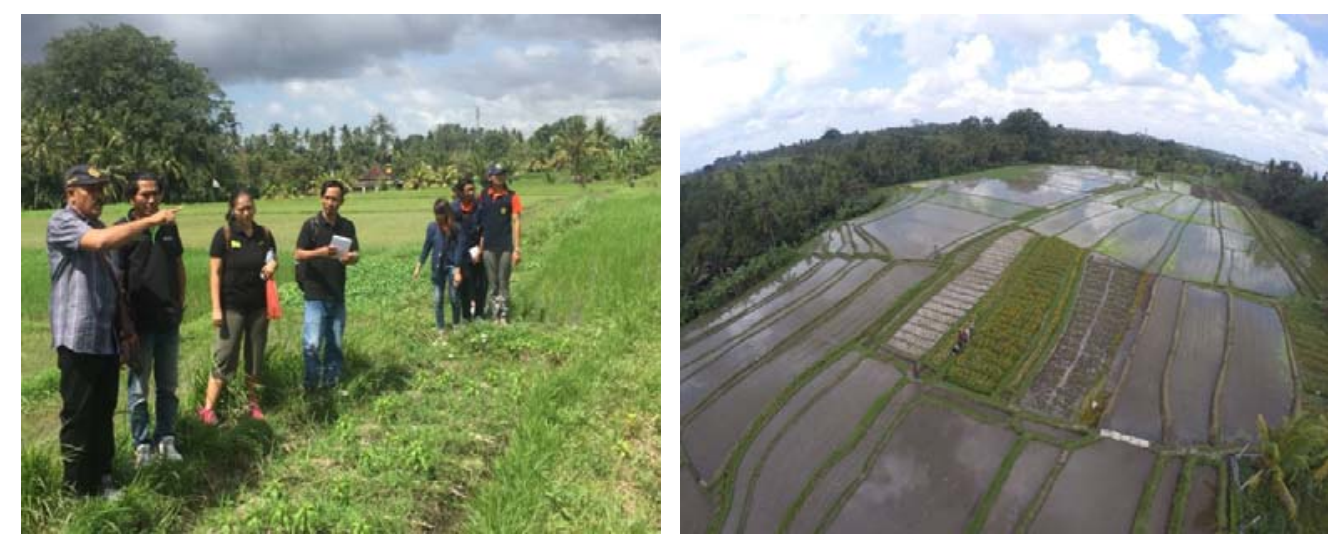

Gambar 1. Pemetaan Jalur Trekking

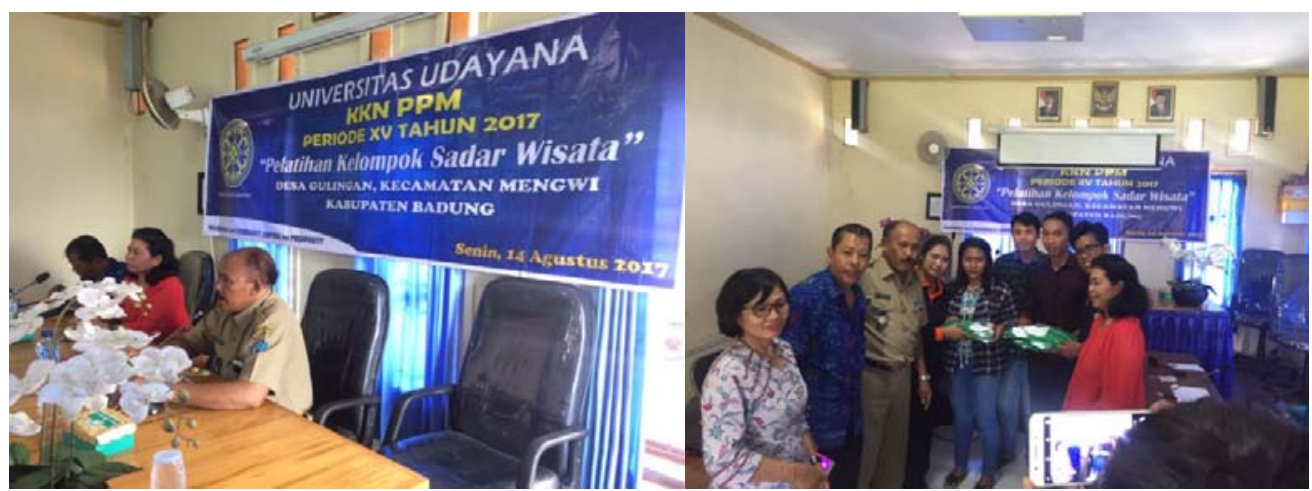

Gambar 2. Pelatihan Teknik guiding dan bahasa Inggris

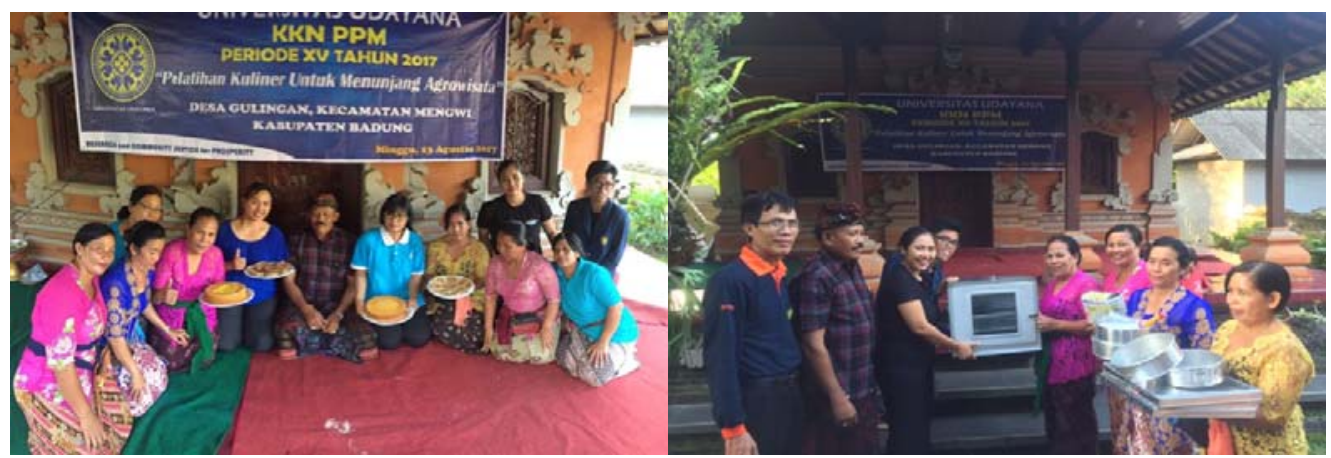

Gambar 3. Pelatihan Pengolahan hasil Pertanian 


\section{UCAPAN TERIMA KASIH}

Penulis mengucapkan terima kasih kepada KEMENRISTEK DIKTI atas dana yang diberikan lewat program KKNPPM, Rektor Universitas Udayana, Ketua LPPM beserta staf terima kasih atas tenaga yang diberikan dalam pelaksanaan di lapangan, sehingga pengabdian kepada masyarakat terlaksana sesuai rencana.

\section{DAFTAR PUSTAKA}

Badan Statistik kabupaten Badung Bali. 2012. Kabupaten Badung dalam Angka. Monografi Desa Gulingan. 2010.

Goodwin, H. 2000. Pro poor tourism, dalam Journal D+C 5/2000, September-Oktober, Jerman.

Model Pengembangan Agrowisata di Bali. Wayan Windia, Made Wirartha, Ketut Suamba, dan Made Sarjana. Jurusan Sosial Ekonomi Fakultas Pertanian Universitas Udayana Denpasar. http://ejournal.unud.ac.id/abstrak/\%2813\%29\%20soca-windia\%20dkk-agrowisata\%282\%29.pdf

Deptan, 2005. “Agrowisata Meningkatkan Pendapatan Petani” pada http://database.deptan.go.id.

Pitana, I Gde. 2002. "Pengembangan Ekowisata di Bali". Makalah Disampaikan pada Seminar Ekowisata di Auditorium Universitas Udayana pada tanggal 29 Juni 2002. 